\title{
LA DOCTRINA DE LOS ACTOS PROPIOS Y LA INTERPRETACIÓN DEL CONTRATO*
}

\section{THE DOCTRINE OF SELF ACTS AND THE INTERPRETATION OF CONTRACTS}

\author{
Mariana Bernal Fandiño**
}

Fecha de recepción: 2 de marzo de 2010 Fecha de aceptación: 19 de marzo de 2010

* Este artículo hace parte de los trabajos desarrollados en el marco del Doctorado en Ciencias Jurídicas de la Pontificia Universidad Javeriana.

** Abogada de la Pontificia Universidad Javeriana, máster 2 en Derecho Comercial y máster 2 en Derecho Internacional privado de la Universidad de París II. Estudiante de doctorado en Ciencias Jurídicas de la Pontificia Universidad Javeriana. Actualmente es profesora investigadora del Departamento de Derecho Privado de la Facultad de Ciencias Jurídicas de la Pontificia Universidad Javeriana. 


\section{RESUMEN}

Este artículo es uno de los productos del proyecto de investigación "Interpretación y aplicación del derecho privado" adelantado por el Grupo de Investigación en Derecho Privado de la facultad de Ciencias Jurídicas de la Pontificia Universidad Javeriana. Este texto pretende demostrar la utilidad de la doctrina de los actos propios como herramienta para la interpretación de los contratos. Con este fin, en primer lugar, se explica la noción de acto propio, una figura que no ha sido analizada en profundidad en Colombia. Se analiza el concepto de manera general para luego revisar su relación con el principio de la buena fe, desde la perspectiva de su función integradora e interpretativa del derecho. En segundo lugar, se analizan los requisitos de aplicación de la doctrina y finalmente sus límites, temas indispensables para el uso adecuado de la misma en el proceso interpretativo de los contratos.

Palabras clave: actos propios, buena fe, interpretación contractual.

Palabras clave descriptor: Derecho civil, interpretación del derecho, actos propios.

\section{ABSTRACT}

This article is one of the products of the research project "Interpretation and Application of Private Law" that has been carried out by the Study Group on Private Law in the Pontificia Universidad Javeriana. In this text we intend to prove that the actos propios doctrine is a useful tool of contractual interpretation. The figure has barely been studied in Colombia that is the reason why we start by explaining the notion of that doctrine in particular as a derivation of the good faith principle given its binding force and interpretation function. Then, the article analyses the application requirements of the figure and finally it describes its limits, essential subjects to an adequate use of the doctrine during the interpretative process of the contracts.

Key words: actos propios, good faith, contractual interpretation.

Key words plus: Civil law, Law, Interpretation and Construction, Proper Acts. 


\section{INTRODUCCIÓN}

Desde el derecho romano, encontramos la regla del venire contra factum proprium non valet, según la cual nadie puede cambiar su propio designio en perjuicio de otro. Esta regla refleja la importancia del comportamiento coherente en el tráfico jurídico y su origen se remonta al derecho romano ${ }^{1}$, aunque algunos autores consideran que la regla como tal debe ser atribuida a Azzo en el derecho intermedio ${ }^{2}$ dado que en el digesto su aplicación aparece solo en casos concretos.

La regla del venire contra factum proprium tiene en nuestra opinión múltiples manifestaciones ${ }^{3}$, aunque se ha tradicionalmente equiparado en nuestro sistema jurídico a la doctrina de los actos propios. Esta doctrina, si bien no ha tenido un desarrollo tan amplio en Colombia como ha sucedido en otros países de Iberoamérica $^{4}$, en los últimos años se puede observar que nuestros jueces así como los tribunales de arbitramento utilizan cada vez más esta herramienta en sus decisiones, pues es indispensable que las partes de un contrato observen un comportamiento coherente en las diferentes fases del mismo ya que, en muchas ocasiones, la conducta de una persona puede determinar la de otra a través de sus actos.

Consideramos que el uso de los actos propios se presenta como una herramienta importante en la interpretación de los contratos, teniendo en cuenta que entendemos como interpretación, la operación que busca el significado jurídicamente relevante del acuerdo contractual ${ }^{5}$. En este sentido, la constatación de la voluntad traducida en el acuerdo, y no la voluntad de cada contratante, es lo que hace que la interpretación sea objetiva y refleje la expresión socialmente relevante del acuerdo de las partes. Como lo explica BETTI, el cometido de la interpretación es el de reconstruir el significado que debe atribuirse a la declaración o conducta manifestada, según las concepciones dominantes de la conciencia social, del lenguaje común, de la práctica de la vida, los usos, etc. ${ }^{6}$

1 Martha Lucía Neme, "Venire contra factum proprium, Prohibición de obrar contra los actos propios y la protección de la confianza legítima, tres maneras de llamar a una antigua regla emanada de la buena fe". En tomo III. Estudios de derecho civil, obligaciones y contratos. pág. 12. Universidad Externado de Colombia. Bogotá. (2003).

2 Alejandro Borda La teoría de los actos propios. pág. 19. Abeledo Perrot. Buenos Aires. (2000).

3 Figuras como el estoppel del derecho anglosajón, la verwirkung del derecho alemán y suizo o la confianza legítima, que cobra cada vez más fuerza en Europa, así como en nuestro derecho. Ver Mariana Bernal. El deber de coherencia y la regla del venire contra factum proprium, Revista International Law, $\mathrm{n}^{\circ}$ 13, Bogotá, julio-diciembre (2008).

4 Autores como Díez-Picazo \& Puig Brutau en España, López Mesa \& Borda en Argentina, López Santa-María, Fueyo Laneri \& Ekdahl Escobar en Chile, entre otros, han abordado el tema de forma profunda, coincidiendo en la importancia de la figura y la necesidad de su clara delimitación.

5 Bianca, Massimo. "Derecho civil". Tomo 3. El contrato. Traducción de Fernando Hinestrosa \& Édgar Cortés. Pág. 443. Ed. Universidad Externado de Colombia. Bogotá. (2007).

6 Emilio Betti. Teoría general del negocio jurídico, Traducción de Martín Pérez, A. Pág. 275. Ed. 
Ahora bien, al interpretar el contrato pueden presentarse situaciones de contradicción (ya sea el comportamiento observado por las partes, las disposiciones mismas del acuerdo, etc. ...) que vuelvan aún más compleja esta labor. Es imposible pretender tener normas claras que abarquen cada caso en particular y en la actualidad se afirma que se ha abandonado ese idealismo exegético para dar paso a la aplicación de herramientas como las doctrinas y los principios que facilitan la ya difícil tarea del intérprete?

Así, el juez debe trazar límites en las posibilidades de contradicción de las partes, para lograr un equilibrio entre la libertad, la seguridad y la coherencia contractual. No deja de ser un tema polémico, pues se enfrentan distintas posiciones. Por una parte, existe la opinión de que un principio según el cual deba imponerse al contratante un deber de no contradecirse en detrimento de otro es necesario para la vida en sociedad que supone una cierta estabilidad o confianza, donde la coherencia de los comportamientos individuales aparece como el cimiento del orden jurídico y moral. Por otra parte, se considera que, por el contrario, no sería oportuna una norma restrictiva que limite las iniciativas de la libertad individual y actúe siguiendo un interés propio a veces cambiante. Adicionalmente, no son pocos los que critican el uso de la doctrina de los actos propios como una peligrosa herramienta que crea incertidumbre para las partes ${ }^{8}$.

Pretendemos entonces con este artículo, dada la importancia teórica y práctica del tema, analizar la noción de actos propios desde su relación con el principio de buena fe i), sus requisitos de aplicación ii) y sus límites iii), como una guía para la interpretación de los contratos.

\section{METODOLOGÍA}

El método utilizado en este trabajo ha sido el de la dogmática jurídica. Así, la investigación se ha desarrollado en torno al análisis de la doctrina de los actos propios con la finalidad de demostrar que representa una herramienta útil para la interpretación de los contratos. La construcción de la propuesta ha sido predominantemente deductiva sin perjuicio de la revisión de algunas sentencias y laudos que ilustran la propuesta.

Comares, Granada. (2000). Esta posición de prevalencia de la declaración sobre la voluntad real de las partes, se aparta de la interpretación en la doctrina clásica latina en la que prevalece la voluntad real de las partes sobre la declaración de la misma. Sobre este último sistema de interpretación, ver Guillermo Ospina Fernández. Teoría general del contrato y de los demás actos jurídicos o negocios jurídicos. Pág. 405 y ss. Ed. Temis, cuarta edición. Bogotá. (1994).

7 En este sentido, Llamas Pombo afirma que un elemento común a las corrientes metodológicas actuales es la propensión a la "superación de los positivismos". Eugenio Llamas Pombo. Orientaciones sobre el concepto y el método del derecho civil. Pág. 197. Ed. Pontificia Universidad Javeriana. Segunda edición. Bogotá. (2009).

8 María Fernanda Ekdahl Escobar. La doctrina de los actos propios. Pág. 28. Ed. Jurídica de Chile. Santiago de Chile. (1989). 


\section{La doctrina de los actos propios y el principio de buena fe}

Los principios generales del derecho cumplen, entre otras, la función de servir de orientadores para la interpretación ${ }^{9}$. La doctrina de los actos propios como derivada del principio de la buena fe, cumple esta función. Para explicarlo, comenzaremos por analizar la noción de la doctrina de los actos propios (A) para luego situar el principio de buena fe en el derecho de los contratos (B).

\section{La doctrina de los actos propios: concepto}

La doctrina de los actos propios no ha sido estudiada a profundidad en Colombia por parte de la doctrina. Sin embargo, nuestros jueces (principalmente en las altas cortes y tribunales de arbitramento) lo utilizan cada vez más en sus decisiones. Por esta razón, consideramos importante analizar esta doctrina y la forma como puede utilizarse como una herramienta para la interpretación de los contratos.

La doctrina de los actos propios es tal vez la figura que más se ha relacionado en el ordenamiento jurídico colombiano con la regla del venire contra factum proprium non valet. ENNECCERUs explica que según esta regla:

"A nadie le es lícito hacer valer un derecho en contradicción con su anterior conducta, cuando esta conducta, interpretada objetivamente según la ley, según las buenas costumbres o la buena fe, justifica la conclusión de que no se hará valer el derecho, o cuando el ejercicio posterior choque contra la ley, las buenas costumbres o la buena fe"10.

Este tratadista alemán, al referirse a la mencionada regla, la equipara al estoppel anglosajón, y manifiesta que el Tribunal Supremo español también consagra la regla en su conocida doctrina de los actos propios de acuerdo con la cual nadie puede ir válidamente contra sus propios actos. Compartimos esta opinión en cierta medida, pues si bien como se comentó en la introducción del presente texto consideramos que la regla del venire contra factum proprium tiene diversas manifestaciones, cada una de ellas presenta particularidades que las hacen distinguirse unas de otras ${ }^{11}$.

9 Los principios generales del derecho sirven de fundamento al ordenamiento jurídico, y cumplen funciones de interpretación e integración de las normas. DeL VeCCHIO, en su obra sobre los principios generales del derecho, explica que de las normas particulares formuladas por el legislador no siempre puede obtenerse un principio capaz de resolver los nuevos casos que se presentan, la función del juez es posible, pues la misma ley ha acogido, además de la interpretación analógica, los principios generales del derecho. GIORGIO DEL VeCCHIO. Los principios generales del derecho. Pág. 58. Ed. Bosch. Barcelona. (1971). Sobre las funciones del principio general de la buena fe ver Jesús GonzÁlez Pérez. El principio general de la buena fe en el derecho administrativo. Págs. 77 y ss. Tercera edición. Ed. Civitas. Madrid. (1999).

10 Ludwig EnNecCerus. Tratado de derecho civil, parte general. Pág. 482. Ed. Bosch. Barcelona. (1935).

$11 \mathrm{Al}$ respecto ver MARIANA BERNAL. El deber de coherencia en los contratos y la regla del venire contra factum proprium. Revista International Law. nº 13. Bogotá. julio-diciembre del 2008. Pág. 291. 
Siguiendo entonces con el concepto de los actos propios, López Mesa en su obra sobre el tema explica que de acuerdo con esta doctrina "nadie puede variar de comportamiento injustificadamente, cuando ha generado en otros la expectativa de comportamiento futuro"12. Se constituye así un límite al ejercicio de un derecho subjetivo con el fin de obtener, en las relaciones jurídicas, un comportamiento consecuente de las personas y el respeto del principio de la buena fe.

Es pertinente aclarar que esta noción no debe confundirse con la doctrina sustantiva de los efectos del consentimiento. En efecto, es claro que una parte en un contrato no puede retirarse unilateralmente, pero ello se entiende no como una consecuencia de la doctrina de los actos propios sino como una consecuencia del contrato (C.C., art. 1602).

La doctrina de los actos propios ha sido generalmente asociada con el principio general de la buena fe, considerándose una derivación del mismo. Incluso, algunos autores han ido más allá1 ${ }^{13}$, al calificar la doctrina como un principio general del derecho. En nuestro país, los jueces han calificado la doctrina como un principio, como lo demuestra una sentencia reciente de la Corte Constitucional que establece que "es preciso señalar que la entidad accionada vulneró el derecho al debido proceso de la demandante al desconocer los principios de buena fe, confianza legítima y respeto del acto propio"14.

Tal calificación es discutible puesto que la aplicación de los actos propios contiene múltiples excepciones y es de aplicación residual. Por ello, compartimos la opinión de AlEJANDRo BoRDA, quien afirma que la teoría de los actos propios es una regla de derecho, no un principio, pues considera que los principios generales no admiten excepciones, abarcan una generalidad de situaciones y son base de una estructura que no acepta una idea aún más amplia $^{15}$.

Ahora bien, para entender la función de los actos propios como herramienta de interpretación de los contratos, es importante precisar la relación que existe con la buena fe contractual, para lo cual es indispensable delimitar lo que en este contexto entendemos como buena fe.

12 Marcelo López Mesa. La doctrina de los actos propios en la jurisprudencia. Edición Depalma. Buenos Aires. (1997).

13 EKDAHL ESCOBAR, MARIA FERNANDA, ob.cit, pág 26; FUEYO LANERI, FERNANDO. Instituciones de Derecho Civil Moderno, Editorial Jurídica de Chile, Santiago, 1990, pág. 319; LÓPEZ MESA, MARCELO, La doctrina de los actos propios y su importancia práctica en el derecho argentino y español. Proyecciones de la misma en Latinoamérica. principales aspectos y requisitos de aplicación, disertación del 10 de Septiembre de 2007 en el marco del V Congreso Iberoamericano de Derecho Civil en Cartagena, Colombia; GARCÍA DE ENTERRÍA, EDUARDO "La doctrina de los actos propios y el sistema de la lesividad”, en Revista de administración pública, No 20 , Madrid, 1956, pág. 72 .

14 Sentencia de la Corte Constitucional T-075 del 2008. M.P. Manuel José CePeda Espinosa.

15 Alejandro Borda. Ob. cit. Pág. 56. 


\section{El principio de buena fe}

Es necesario diferenciar lo que se entiende por buena fe y lo que se considera buena fe como principio general del derecho. Según el Consejo de Estado de Colombia, la buena fe a secas se utiliza para precisar supuestos de hecho en casos particulares, mientras que como principio general del derecho se refiere a una apreciación de las personas que al realizar actos jurídicos estén motivados por una actitud honesta, leal, tanto en el ejercicio del derecho, como en el cumplimiento de sus obligaciones ${ }^{16}$. El principio de buena fe, explica LARENZ, implica que se debe fidelidad a la palabra dada, y no defraudar la confianza, indispensable para las relaciones humanas, y añade que es un "módulo necesitado de concreción", pero no a través de un juicio subjetivo, sino por el contrario, de un intérprete que se ajuste a las exigencias generalmente vigentes de la justicia ${ }^{17}$.

Debe tenerse en cuenta que si bien los principios generales del derecho no requieren para su existencia la consagración en una norma jurídica, en Colombia el principio de la buena fe, de origen civil, desarrollado además en el Código de Comercio, tiene un rango constitucional desde que se elevó a ese nivel con la Constitución de 1991. En efecto, el artículo 83 de la misma determina que "las actuaciones de los particulares y de las autoridades públicas deberán ceñirse a los postulados de la buena fe, la cual se presumirá en todas las gestiones que aquellos adelanten ante éstas". Del artículo anterior se pueden deducir dos componentes:

Por una parte, se encuentra un deber ser del obrar de la administración en todas sus actuaciones, lo que a su vez encuentra su contrapartida en la obligación de los particulares de observar una misma y regular conducta en su acción frente a las autoridades.

Por otra parte, predica el deber y la obligación del Estado y de los particulares de obrar con lealtad, sinceridad y ajustados a una conciencia recta, en las actuaciones que se originan en la celebración de contratos, basados en la colaboración y confianza.

La buena fe es una noción muy amplia con diversas manifestaciones, que a su vez han sido estudiadas y clasificadas de varias formas. La clasificación tradicional de la buena fe establece una diferencia entre buena fe subjetiva y buena fe objetiva. Se entiende por buena fe subjetiva la condición de un sujeto en una situación jurídica dada, con referencia al conocimiento que tenga de las circunstancias generales de la misma, es decir, la convicción que tiene una persona de que su comportamiento es regular y permitido. Por otra parte, la

16 Sentencia del Consejo de Estado, Sala de Consulta y Servicio Civil, 17 de abril de 1996. C.P. Roberto SuÁrez Franco.

17 Karl Larenz. Derecho de obligaciones. En Revista de Derecho Privado. Tomo 1. Traducción de Jaime Santos Briz. Madrid. (1958). Pág. 142. 
buena fe objetiva se considera una regla de conducta, un comportamiento recto y honrado que debe manifestarse en las diferentes fases del tráfico negocial $^{18}$. Teniendo en cuenta el contexto en que se desarrolla este artículo, nos vamos a concentrar en esta última clasificación, puesto que la buena fe en su significado de comportamiento o conducta puede ser tomada como criterio de apreciación o de interpretación de los actos jurídicos ${ }^{19}$.

Así, la buena fe se encuentra presente desde el momento de la negociación del contrato, donde se exige un deber de lealtad, de confidencialidad, de información, que se extiende al momento de celebrar el contrato y acompaña su ejecución y terminación.

Ahora bien, sobre la buena fe en los contratos, algunos autores han distinguido la buena fe contractual de la buena fe de los contratantes. En la primera visión se trata la buena fe como una regla de interpretación del contrato, una forma de determinar a qué se obligan las partes, mientras en el segundo caso se entiende como una exigencia de comportamiento ${ }^{20}$. Pero en ambas visiones, el actuar de buena fe supone una coherencia en las relaciones contractuales, fundamental en la construcción de la doctrina de los actos propios.

Si bien la buena fe no tiene un contenido preestablecido, es un principio de solidaridad contractual en el que se observan dos aspectos fundamentales, el de la salvaguarda, que pretende proteger el interés de la contraparte y el de la lealtad. La buena fe exige no suscitar una falsa confianza, no especular con esa falsa confianza y no desconocer la confianza razonable generada en la contraparte ${ }^{21}$.

\section{Requisitos de aplicación de la doctrina de los actos propios}

El comportamiento de las partes en los contratos, ya sea cuando manifiestan de manera expresa su voluntad o si lo hacen de forma tácita, es fuente de interpretación. El intérprete del contrato debe, por lo tanto, revisar si se presentan incoherencias y confrontarlas con la presunta voluntad de las partes al contratar. De esta manera, se utiliza la doctrina de los actos propios de una forma objetiva, sin necesidad de desentrañar la real intención de las partes al contratar, sino limitándose a la exteriorización de sus actos.

La Corte Constitucional en la sentencia T-295 de 1999 se refiere con respeto al acto propio como un tema cuyo sustento jurídico es el principio constitu-

18 Sobre las clasificaciones de la buena fe, ver Arturo Solarte. Buena fe contractual y deberes secundarios de conducta. En Revista Universitas. n 108. Diciembre del 2004. Pág. 286.

19 Jorge Santos Ballesteros. Instituciones de responsabilidad civil. Pág. 99. Tomo I. Pontificia Universidad Javeriana. Bogotá. (2006).

20 Romain Loir, Les fondements de l'exigence de bonne foi en droit français des contrats. Pág. 11. Ecole doctorale $\mathrm{n}^{\circ}$ 74. Lille 2. (2002).

21 Massimo Bianca. Ob. cit. Págs. 443 y ss. 
cional de la buena fe, que sanciona como inadmisible toda pretensión lícita pero objetivamente contradictoria con respecto al propio comportamiento efectuado por el sujeto. En el mismo sentido, en sentencia de constitucionalidad, la Corte igualmente se refiere a este principio como "una exigencia de honestidad, confianza, rectitud, decoro y credibilidad que otorga la palabra dada, a la cual deben someterse las diversas actuaciones de las autoridades públicas y de los particulares entre sí y ante éstas, la cual se presume, y constituye un soporte esencial del sistema jurídico"22.

La claridad en los requisitos para la aplicación de la teoría de los actos propios es fundamental para la seguridad en el tráfico jurídico. En este sentido, nuestra jurisprudencia los determina de la siguiente forma ${ }^{23}$ :

\section{Una conducta jurídicamente anterior, relevante y eficaz}

Sobre este requisito, la Corte explica que debe tratarse de una conducta ejecutada dentro de una relación jurídica que suscite la confianza de un tercero. Adicionalmente, se refiere a la necesidad de la eficacia de la primera conducta que emite un sujeto y que contradice otra conducta posterior contradictoria con aquella. En este punto vale la pena comentar la discrepancia que existe entre estudiosos del tema sobre la posibilidad de aplicar la doctrina de los actos propios frente a una conducta viciada por error, dolo o violencia. Así por ejemplo, Luis DíEz-PicAzo plantea la disyuntiva que se presenta entre el no poderse alegar error por proteger la confianza que la propia conducta suscitó en la otra parte en la voluntad inicial o si, por el contrario, la doctrina de los actos propios no debe aplicarse si de lo que se trata es de rectificar las consecuencias de un error ${ }^{24}$. En opinión de LóPEZ MesA, la presencia de un vicio de la voluntad de cierta significación impide la aplicación de la doctrina. Ahora bien, es importante para el intérprete del contrato que pretende vislumbrar la voluntad contractual, precisar qué se entiende por un vicio de cierta significación. Para FueYo LANERI ${ }^{25}$, no va contra sus propios actos quien pide la anulación de un contrato por vicio del consentimiento, pero esto como regla general, pues el autor admite que el mismo Código Civil chileno establece excepciones como, por ejemplo, el caso del artículo 1683 según el cual la nulidad absoluta puede alegarse por todo el que tenga interés en ello, "excepto el que ha ejecutado el acto o celebrado el contrato, sabiendo o debiendo saber el vicio que lo invalidaba ...". Desde otro ángulo, Alejandro BORDA comenta que es "ir contra los propios actos atacar de nulidad un con-

22 Corte Constitucional, Sentencia C-131 del 2004. M.P. Clara Inés Vargas.

23 Corte Constitucional, Sentencia T-295 de 1999. m.P. Alejandro Martínez Caballero.

24 Luis Diez-Picazo. La doctrina de los propios actos. Pág. 209. Ed. Bosch. Barcelona. (1963). Sobre las distintas posiciones al respecto ver MARCElo LóPEz MeSA. La doctrina de los actos propios. Pág. 50. Editorial Reus. Buenos Aires. (2005).

25 Fernando Fueyo Laneri. Ob. cit. Pág. 351. 
trato cuando le resulta incómodo o perjudicial si lo ha considerado válido por años y se ha beneficiado de él”26.

Al respecto, la Corte Constitucional ha manifestado que los particulares no están obligados a soportar los errores de las entidades públicas y cuando tienen derechos a su favor creados por la administración, se les deben garantizar hasta que no haya decisión judicial que los desvirtúe ${ }^{27}$. Y en cuanto a los particulares, la corte determina:

“... cuando la tutela, como en el presente caso, no es (dentro de la estructura de la acción de tutela) propiamente contra autoridad pública, entonces, con igual razón hay que proteger las determinaciones ya tomadas, que han constituido un derecho adquirido para el beneficiado y que no pueden ser modificadas sin la autorización del favorecido porque se ha consolidado en él una situación jurídica concreta, que al ser variada afecta la buena fe y la seguridad jurídica" ${ }^{28}$.

\section{El ejercicio de una facultad o de un derecho subjetivo por la mis- ma persona o centros de interés que crea la situación litigiosa, debido a la contradicción -atentatoria de la buena fe- existen- te entre ambas conductas.}

Al explicar este requisito, la Corte retoma el análisis de AlejANDro Borda, quien manifiesta que para aplicar la teoría de los actos propios es necesaria la existencia de una "pretensión contradictoria". Borda sugiere tomar un concepto más amplio del que se entiende tradicionalmente por pretensión, particularmente desde un punto de vista procesal. De esta forma, se engloban no solamente declaraciones sino fundamentalmente conductas. Esto implica un esfuerzo adicional por parte del intérprete del contrato, quien debe tener en cuenta no sólo la literalidad del contrato, sino el comportamiento de las partes y sus variaciones, que por supuesto, podrán estar justificadas por las circunstancias del caso, intereses sociales prevalecientes, o cuando han cambiado las condiciones existentes al producirse la conducta vinculante. Se agrega además, que la pretensión puede ser tanto judicial como extrajudicial ${ }^{29}$.

Hasta ahora nos hemos referido, frente a este requisito, a las conductas propiamente positivas, ¿qué sucede entonces con el silencio de las partes?

26 Alejandro Borda. Ob. cit. Pág. 88.

27 La sentencia de la Corte Constitucional T-336 del 15 de julio de 1997, M.P. José Gregorio HernándeZ determina: "Como ya lo ha señalado la jurisprudencia, los particulares no tienen porqué correr con las consecuencias negativas de los errores de las entidades públicas y, cuando tienen derechos a su favor, creados por actos de la administración -así éstos provengan de equivocaciones cometidas por ella- se les debe garantizar, como lo hace el Código Contencioso Administrativo, que tales derechos permanecerán incólumes en tanto no haya una decisión judicial que los desvirtúe, previas las reglas del debido proceso".

28 Sentencia T-295 de 1999, M.P. Alejandro Martínez Caballero.

29 Alejandro Borda. Ob. cit. Pág. 76. 
Si resulta difícil en muchos casos interpretar la voluntad expresada, el intérprete se enfrenta a una dificultad mucho mayor cuando se encuentra con el silencio de las partes como posible manifestación de voluntad ${ }^{30}$. Si bien el principio general nos indica que el silencio no es una forma idónea de manifestar la voluntad contractual, existen excepciones, como los casos en que la ley le da efecto vinculante al silencio, o las partes lo hacen.

Ahora bien, en el tema del silencio hay situaciones que no encajan en las excepciones anteriores y son muy interesantes de analizar como es el tema de la prescripción y los actos propios. Cuando los actos propios consisten en omisiones o en una conducta pasiva, se produce una situación semejante a la prescripción extintiva. Así, como lo afirma PUIG BRUTAU, "en el caso de protección dispensada por equidad a quien ha confiado en la apariencia creada por la actitud pasiva de alguien, es decir, cuando el silencio ha podido ser interpretado de buena fe como asentimiento o como prueba de la inexistencia del derecho que luego se intenta hacer valer, en tales casos nos encontramos con un problema de aplicación de la doctrina de los actos propios"31. Por esta razón, la doctrina mencionada puede ser en estos casos una guía importante para el intérprete en la determinación del silencio como una declaración de voluntad, puesto que si bien no se trata de una real declaración de voluntad, puede producir el mismo resultado, si las circunstancias lo ameritan.

Un ejemplo reciente de un conflicto en materia de seguros sometido a la justicia arbitral nos puede ayudar a entender mejor la situación. En efecto, en el laudo arbitral del 5 de marzo del 2009 que dirimió las diferencias entre la Beneficencia del Valle del Cauca EICE y la Previsora S.A. Compañía de Seguros, la aseguradora establece en la póliza de seguros denominada Multirriesgo que no responderá por perjuicios causados por el asegurado hasta tanto éste no sea condenado a reparar perjuicios. El asegurado acude ante la aseguradora tan pronto lo demandan, pero la aseguradora contesta que de acuerdo con lo estipulado en el contrato no responderán hasta tanto no se obtenga la sentencia. El asegurado espera entonces a obtener sentencia para acudir nuevamente ante la aseguradora. Ésta le contesta que ya prescribió su derecho y por lo tanto no están obligados a responder. El tribunal decide que el comportamiento de la aseguradora no es coherente y se aprovecha de la confianza suscitada en el asegurado. LARENZ al respecto afirma que es válido oponer a la excepción de prescripción "la objeción de 'ejercicio inadmisible del derecho' cuando el deudor mediante su anterior conducta, aunque sea involuntaria, hubiese dado motivo al acreedor para prescindir de interrumpir la prescripción...”32. En este caso vemos la imposibilidad de la aseguradora de excepcionar por prescripción

30 Ibíd. Pág. 102.

31 José Puig Brutau. Estudios de derecho comparado. La doctrina de los actos propios. Pág. 119. Ed. Ariel. Barcelona. (1951).

32 Karl Larenz. Ob. cit. Pág. 151. 
por ir en contra de sus propios actos, pues si bien no se trata de una verdadera declaración de voluntad, se trata de un supuesto que debe producir el mismo resultado y, por ende, debe ser reconocido en virtud del principio de la buena fe por quien esté a cargo de interpretar el contrato.

\section{La identidad del sujeto o centros de interés que se vinculan en ambas conductas}

Acerca de este último requisito, es interesante analizar si los sujetos que intervienen y a quienes les afectan las dos conductas deben ser los mismos o si basta con un solo sujeto común en dos relaciones distintas que se comporte de manera incoherente. Si bien los casos más comunes en los que la jurisprudencia y tribunales arbitrales han aplicado la doctrina de los actos propios han versado sobre situaciones con identidad de sujetos, existen casos en los que se ha alegado la incoherencia del comportamiento de un sujeto frente a escenarios similares en relaciones distintas ${ }^{33}$, lo cual es perfectamente acorde con el tenor del requisito establecido por la Corte Constitucional que claramente se refiere a "la identidad del sujeto", a diferencia de lo que opinan autores como FueYo LANERI que consideran que debe darse la identidad de los sujetos que actúan y se vinculan en ambas conductas ${ }^{34}$.

Un ejemplo interesante en el cual se le exige coherencia a una de las partes con base en su comportamiento anterior, frente a una relación contractual con un sujeto diferente, consiste en un caso sometido a la justicia arbitral en materia de contratos de interconexión entre dos operadores de telecomunicaciones, en el cual se alega que una de las partes va en contra de sus actos propios, pues varió las condiciones de interconexión con un operador y otro. Adicionalmente, para analizar este conflicto debe tenerse en cuenta que el regulador, la CRT, había determinado que por razones de protección a la libre competencia no podía haber trato discriminatorio, es decir, el operador debe ofrecer las mismas condiciones de interconexión para todos.

Por otra parte, al analizar si una de las partes ha actuado en contra de sus propios actos, quien interpreta el contrato debe tener en cuenta, frente a este requisito, que se refiere a los sujetos involucrados, que la Corte se refiere a identidad de sujetos o centros de interés. Estos últimos han sido desarrollados por la jurisprudencia española que en tratándose de sujetos físicamente distintos el centro de interés es el mismo, como ocurre en los casos de representación y sucesión. En efecto, en casos de representación, los actos del representante se imputan al representado, de manera que éste, en principio, no puede contradecir los actos realizados por aquél, pues se está afectando

\footnotetext{
33 Ver laudo arbitral del 7 de noviembre del 2007 entre Telefónica Móviles Colombia S.A y la Empresa de Telecomunicaciones de Bogotá, S.A.

34 Fueyo Laneri, Fernando. Ob. cit. Pág. 316.
} 
un mismo interés ${ }^{35}$. En materia de sucesiones, a nadie le es lícito desconocer la eficacia de los actos realizados por su causante.

Otra problemática que se deriva del requisito de identidad de los sujetos radica en los sujetos colectivos, pues éstos expresan su voluntad a través de órganos, y las declaraciones de voluntad emitidas por esos órganos que actúan dentro de la esfera de su competencia tienen el carácter de actos propios del sujeto colectivo. Ahora bien, el órgano es distinto de las personas físicas que lo componen, éstas solo actúan como órganos del sujeto cuando desempeñan funciones del mismo. Así, ni los actos del sujeto colectivo tienen el carácter de actos propios para las personas físicas que actúan como titulares de sus órganos, ni los actos que éstas realizan por fuera de sus funciones con respecto del sujeto colectivo se consideran como actos propios de éste. A manera de ilustración, en el caso de una sociedad, no sería lógico aplicar la doctrina de los actos propios a un socio que pretende impugnar una decisión de la asamblea que vulnere sus derechos ${ }^{36}$.

Finalmente, del análisis de este último requisito que establece la Corte se desprende la posibilidad de aplicar la doctrina de los actos propios a los jueces. Este tema también se ha discutido en la doctrina, pues no hay unanimidad al respecto. Nuestra jurisprudencia ha manifestado en sentencia de constitucionalidad que "esta obligación de respeto por los propios actos implica, no sólo el deber de resolver casos similares de la misma manera, sino, además, el de tenerlos en cuenta de manera expresa, es decir, la obligación de motivar sus decisiones con base en su propia doctrina judicial" ${ }^{\prime 37}$.

Al considerar los anteriores requisitos, es evidente que no basta la mera contradicción de un acto previo con otro posterior. Nuestro sistema contractual se basa en la autonomía de la voluntad de los individuos y debe permitirse desde luego la posibilidad de corregir los errores que se hayan podido cometer. Por esta razón, es fundamental entender que la base de la doctrina de los actos propios se encuentra en las expectativas legítimas creadas con las actuaciones. Es necesario proteger la planeación y que no se le permita a otro que con su incoherencia ocasione un daño.

\section{Límites de la doctrina de los actos propios}

Existen fuertes críticas contra la aplicación de esta doctrina, pues se ha considerado que flota en la imprecisión y con frecuencia se limita a servir de

35 Borda, Alejandro. Ob. cit. Pág. 85.

36 López, Laureano, Presupuestos subjetivos para la aplicación del principio que prohíbe ir contra los propios actos. Publicado por el Centro de Estudios Políticos y Constitucionales. Madrid. (1952). Disponible en www.cepc.es/rap/Publicaciones/Revistas/1/1952_009_011.PDF

37 Sentencia de la Corte Constitucional C-836 del 2001, M.P. EsCOBAR GIL. 
complemento a los argumentos que se basan en los más variados conceptos ${ }^{38}$, de ahí la importancia de tener claros no solamente sus requisitos de aplicación, sino también sus límites.

La doctrina de manera uniforme considera que la regla de los actos propios no puede considerarse una regla absoluta. Es fundamental aplicarla de forma restrictiva siguiendo los límites y requisitos considerados anteriormente, analizando caso por caso para evitar inequidades.

Son múltiples los casos en los cuales la ley misma permite volver sobre las conductas, cambiar de actitud, como es el caso de la oferta que puede ser retractada antes de su aceptación, las circunstancias que llevan a la aplicación de la figura de la imprevisión, la revocabilidad del mandato, la posibilidad de pactar arras precisamente para anticipar la posibilidad del retracto, el cambio del testamento, la renuncia a la herencia, entre muchos otros.

En materia de las nulidades como límite para la doctrina de los actos propios, será el juez quien determine si se presenta abuso o no al alegar la nulidad, pues una cosa es alegar una nulidad por un acto viciado, y otra si después de celebrado un acto nulo o viciado, con la conducta se ratifica el mismo y después se pide la nulidad cuando, por ejemplo, se ha sacado provecho de ese acto. En consecuencia, la doctrina no aplica para los actos que adolezcan de nulidad absoluta, por tanto insubsanables.

Adicionalmente, se trata de una regla de aplicación residual ${ }^{39}$, pues no se utiliza en los casos en que el ordenamiento determina una solución expresa para la contradicción a través de figuras especiales. Un laudo del 14 de octubre del $2009^{40}$ aclara esta situación, pues una de las partes, Lukoil, en las excepciones propuestas, manifiesta que las partes firmaron una transacción, que "produce los efectos de cosa juzgada de conformidad con el artículo 2483 del Código Civil", pero además, en otra de las excepciones declara que las reclamaciones traídas al proceso ya habían sido objeto de acuerdos entre las partes, lo que supone mala fe de la otra parte, Occipetrol, y por lo tanto desconocimiento de sus actos propios. La decisión del tribunal afirma que "siendo residual la regla del venire contra factum proprium, o si se prefiere la doctrina o teoría de los actos propios, no puede ser aplicada preferentemente, haciendo a un lado, de una parte, la voluntas legislatoris, al mismo tiempo que la intentio de la parte convocada, quien, como se memoró, formuló en primer término la excepción que literalmente denominó de 'cosa juzgada".

38 García de Enterría, Eduardo. La doctrina de los actos propios y el sistema de la lesividad. Revista de administración pública. $\mathrm{n}^{\circ}$ 20. Madrid. 1956. pág. 72.

39 Sobre el carácter residual y relativo de los actos propios ver María Fernanda E. EKDAH. Ob. cit. Pág. 38. Fernando Fueyo Laneri. Ob. cit. Pág. 309. Marcelo Lopez Mesa. Ob. cit. Pág. 180. Carlos Ignacio Jaramillo. La doctrina de los actos propios y su proyección en la esfera del derecho de los contratos. En AA.VV. Estudios de Derecho Privado. Tomo I. Universidad del Rosario. Bogotá. 2009. pág. 310.

40 Laudo Arbitral entre Occipetrol S.A. contra Lukoil Overseas Colombia Ltda. 


\section{CONCLUSIONES}

La prohibición de ir en contra de los propios actos ha sido utilizada desde el derecho romano para proteger la coherencia en el comportamiento de las partes en el manejo de sus negocios. Si bien es una noción que debe delimitarse muy claramente para evitar su abuso, es una figura útil para la interpretación de los contratos, puesto que siendo una doctrina que se deriva del principio de la buena fe, aplicada con mesura, constituye una herramienta importante para desentrañar la voluntad traducida en el acuerdo y no solamente la voluntad de cada contratante de forma independiente. Así, atender a las circunstancias particulares de cada caso, no implica un atentado a la seguridad jurídica y en cambio se protege la justicia, siempre que se realice de forma prudente y como producto de un estudio juicioso y profundo. 


\section{BIBLIOGRAFÍA}

Mariana Bernal. El deber de coherencia y la regla del venire contra factum proprium. En Revista International Law. n 13. Bogotá. julio-diciembre del 2008.

Emilio Betтi. Teoría general del negocio jurídico. Traducción de A. Martín Pérez. Ed. Comares. Granada. (2000).

Massimo Bianca. Derecho civil. Tomo 3. El contrato. Traducción de Fernando Hinestrosa, y Édgar Cortés. Ed. Universidad Externado de Colombia. Bogotá. (2007).

Alejandro Borda. La teoría de los actos propios. Abeledo Perrot. Buenos Aires. (2000).

Giorgio del Vecchio. Los principios generales del derecho. Ed. Bosch. Barcelona. (1971).

Luis Díez-Picazo. La doctrina de los propios actos. Ed. Bosch. Barcelona. (1963).

María Fernanda Ekdahl Escobar. La doctrina de los actos propios. Ed. Jurídica de Chile. Santiago de Chile. (1989).

Ludwig Enneccerus. Tratado de derecho civil, parte general. Traducción de Blas Pérez GonzÁlez y José Alguer. Ed. Bosch. Barcelona. (1935).

Fernando Fueyo Laneri. Instituciones de derecho civil moderno. Editorial Jurídica de Chile. Santiago, (1990).

Eduardo García de Enterría. La doctrina de los actos propios y el sistema de la lesividad. En Revista de administración pública. $\mathrm{n}^{\circ} 20$. Madrid. (1956).

Jesús GonzÁlez Pérez. El principio general de la buena fe en el derecho administrativo. Tercera edición. Ed. Civitas. Madrid. (1999).

Carlos Ignacio Jaramillo. La doctrina de los actos propios y su proyección en la esfera del derecho de los contratos. En AA.VV. Estudios de derecho privado. Tomo I. Universidad del Rosario. Bogotá. (2009).

Karl Larenz. Derecho de obligaciones. En Revista de Derecho Privado. Tomo 1. Traducción de Jaime Santos Briz. Madrid. (1958).

Romain Loir. Les fondements de l'exigence de bonne foi en droit français des contrats. Ecole doctorale $\mathrm{n}^{\circ}$ 74. Lille 2. (2002).

Laureano López. Presupuestos subjetivos para la aplicación del principio que prohíbe ir contra los propios actos. Publicado por el Centro de Estudios Políticos y Constitucionales. Madrid. (1952). Disponible en www.cepc.es/rap/Publicaciones/ Revistas/1/1952_009_011.PDF

Marcelo López Mesa. La doctrina de los actos propios. Ed. Reus. Buenos Aires. (2005).

La doctrina de los actos propios en la jurisprudencia. Ed. Depalma. Buenos Aires. (1997).

La doctrina de los actos propios y su importancia práctica en el derecho argentino y español. Proyecciones de la misma en Latinoamérica. Principales aspectos y requisitos de aplicación. Disertación del 10 de septiembre del 2007 en el marco del V Congreso Iberoamericano de Derecho Civil en Cartagena, Colombia.

Jorge López Santa-María. Los intereses devengados por indemnización contractual de perjuicios. Doctrina de los actos propios o estoppel. En Revista de Derecho y 
Jurisprudencia. Tomo LXXXII. $n^{\circ}$ 2. Parte $1^{a}$. Santiago de Chile. mayo-agosto. (1985).

Eugenio Llamas Pombo. Orientaciones sobre el concepto y el método del derecho civil. Ed. Pontificia Universidad Javeriana. Segunda edición. Bogotá. (2009).

Martha Lucía Neme. "Venire contra factum proprium, Prohibición de obrar contra los actos propios y la protección de la confianza legítima. Tres maneras de llamar a una antigua regla emanada de la buena fe". En Tomo III de los Estudios de derecho civil, obligaciones y contratos, Universidad Externado de Colombia. Bogotá. (2003).

Guillermo Ospina Fernández. Teoría general del contrato y de los demás actos jurídicos o negocios jurídicos. Ed. Temis. Cuarta Edición. Bogotá. (1994).

Jose Puig Brutau. Estudios de derecho comparado. La doctrina de los actos propios. Ed. Ariel. Barcelona. (1951).

GuZMÁn Rivas. "La doctrina de los actos propios y el reglamento interno de la empresa". En Contratos. VV.AA. Ed. Jurídica de Chile. (1991).

Jorge Santos Ballesteros. Instituciones de responsabilidad civil. Tomo I. Pontificia Universidad Javeriana. Bogotá. (2006).

Arturo Solarte. Buena fe contractual y deberes secundarios de conducta. En Revista Universitas. $n^{\circ} 108$. Diciembre. (2004).

\section{Sentencias}

Corte Constitucional

Sentencia T-075 del 2008. M.P. MANuel José CePeda EsPinosa.

Sentencia C-131 del 2004. M.P. Clara InÉS VARgas.

Sentencia T-295 del 1999. M.P. Alejandro Martínez Caballero.

Sentencia T-336 de 1997. M.P. José Gregorio HernÁndez.

Sentencia C-836 del 2001. M.P. Escobar Gil.

Consejo de Estado

Sala de Consulta y Derecho Civil. 17 de abril de 1996. C.P. Roberto SuÁrez Franco.

\section{Laudos arbitrales}

Laudo arbitral del 7 de noviembre del 2007 entre Telefónica Móviles Colombia S.A y la Empresa de Telecomunicaciones de Bogotá, S.A.

Laudo arbitral del 14 de octubre del 2009 entre Occipetrol S.A. contra Lukoil Overseas Colombia Ltda.

Laudo arbitral del 5 de marzo del 2009 entre la Beneficencia del Valle del Cauca EICE y la Previsora S.A. Compañía de Seguros. 